\title{
Do conhecimento sociológico à teoria das representações sociais*
}

\author{
ERLando da Silva RêSeS ${ }^{* *}$
}

\begin{abstract}
R esumo: Este artigo apresenta uma discussão em tomo do conceito de representação ou representações na teoria sociológica clássica e contemporânea e, em seguida, apresenta as bases epistemológicas da teoria das representaçoes sociais. O djjetivo é destacar as diferentes concepgões nas duas áreas do conhecimento - sociologia e psicologia social - e ressaltar que o conceito de representagões sociais de Serge Moscovici teve suas origens no conceito de representaçães coletivas de Durkheim.
\end{abstract}

Palavras-chave: epistemologia; representações coletivas; representaçães sociais.

As representações na teoria sociológica clássica e contemporânea

O psicólogo social Serge Moscovici, ao tentar recuperar historicamente o conceito de representações sociais, afirma que este passou por diferentes fases, sendo que os estudiosos da primeira fase estavam mais preocupados com o caráter coletivo das representações do que propriamente com seu conteúdo ou sua dinâmica. Na primeira fase destacam-se: Simmel, Weber e Durkheim.

Simmel percebe que as idéias ou representações são uma espécie de operador que permite ações recíprocas entre os indivíduos para formar a unidade superior, que é a instituição (partido político, I greja etc.). Portanto, elas objetivam passar de um nível molecular para um molar. Esta concepção das representações postas no centro do comportamento e das instituições está

\footnotetext{
* Este artigo é parte da dissertação de mestrado do autor E com a palavra os alunos: estudo das representações sociais dos alunos da rede pública do Distrito $F$ ederal sobre a sociologia no ensino médio (Brasília: Universidade de Brasília, 2004).

** M estre e doutorando em Sociologia pela Universidade de B rasília.
}

integrada a várias tendências da Sociologia (M oscovici apud J odelet, 2001).

Num sentido diferente, Weber faz das representações um quadro de referências e um vetor da ação dos indivíduos, ou seja, a representação seria um saber comum, que tem o poder de antecipar e de prescrever o comportamento dosindivíduos e de programá-lo (M oscovici apud J odel et, 2001).

Para Weber, a vida social - que consiste na conduta cotidiana dos indivíduos - é carregada de significação cultural. Essa significação cultural é dada tanto pela base material como pelas idéias, dentro de uma relação adequada, em que ambas se condicionam mutuamente. Segundo ele, as idéias são juízos de val or que os indivíduos dotados de vontade possuem. $\mathrm{Na}$ obra A ética protestante e o espírito do capitalismo, ele analisa a história do avanço do capitalismo no mundo ocidental e demonstra que as idéias de trabal ho como virtude máxima e vocação do homem, prosperidade como bênção divina, lucro como fator legítimo das relações econômicas contribuíram para fazer avançar o capitalismo, tanto quanto ou mais do que a "acumulação primitiva". Na conclusão dessa obra Weber (1985, p.132) afirma: 
A qui se tratou do fato e da direção em apenas um, se bem que importante ponto de seus motivos. Seria importante investigar mais adiante a maneira pela qual a ascese protestante foi por sua vez influenciada em seu desenvolvimento e caráter pela total idade das condições sociais, especialmente pelas econômicas. Isto porque, se bem que o homem moderno seja incapaz de avaliar o significado de quanto as idéias religiosas influenciaram a cultura e os caracteres nacionais, não se pode pensar em substituir uma interpretação materialista unilateral por uma igualmente bitolada interpretação causal da cultura e da história.

Weber chama a atenção para a importância de se pesquisar as idéias como parte da realidade social e para a necessidade de se compreender a que instâncias do social determinado fato deve sua maior dependência. Porém, a base de seu raciocínio é de que, em qualquer caso, a ação humana é significativa, e assim deve ser investigada, e que cada sociedade para se manter necessita ter "concepções de mundo" abrangentes e unitárias (o modo de encarar o tempo, 0 trabal ho, a divisão do trabalho, a riqueza, o sexo, os papéis sociais etc.) que, em geral, são elaboradas pelos grupos dominantes (M inayo apud Guareschi e J ovchel ovith, 1995).

Já Durkheim partia do princípio de que a ciência, para estudar as representações, tinha de reconhecer a diferença entre o individual e 0 coletivo. Isso porque, para ele, o substrato da representação individual era a consciência própria de cada um, sendo, portanto, subjetiva, flutuante e perigosa à ordem social. Por outro lado, o substrato da representação coletiva era a sociedade em sua totalidade e, por isso, seria impessoal e ao mesmo tempo permanente, garantindo, assim, a ligação necessária entre os indivíduos e, conseqüentemente, a harmonia da sociedade.

Para M arx, as representações estão vinculadas à prática social. J unto com D urkheim, ele mostra a anterioridade da vida social em relação às representações. $M$ as, enquanto para Durkheim a sociedade é a "síntese das consciências", para M arx a consciência emana das relações sociais contraditórias entre as classes e pode ser captada empiricamente como produto da base material, nos "indivíduos determinados, sob condições determinadas". Ele sustenta que a manifestação da consciência se faz por meio da linguagem e realiza um paral el o entre as duas e entre as representações e o real invertido, mostrando como as idéias estão comprometidas com as condições de classe (M inayo apud Guareschi e J ovchelovith, 1995).

$\mathrm{Na}$ obra A ideologia alemã, M arx desenvolve a teoria da consciência definindo-a como o ser consciente. Em sua concepção, a consciência não é separável do ser humano que a desenvolve, e este não é um indivíduo isolado, mas um ser social. Por conseguinte, as representações que os indivíduos elaboram são representações sobre suas relações com os outros indivíduos ou com o meio ambiente. Ele expressa essa idéia da seguinte forma:

As representações que estes indivíduos elaboram são representações a respeito de sua relação com a natureza, ou sobre suas mútuas relações, ou a respeito de sua própria natureza. É evidente que, em todos estes casos, estas representações são a expressão consciente real ou ilusória - de suas verdadeiras relações e atividades, de sua produção, de seu intercâmbio, de sua organização política e social. A suposição oposta é apenas possível quando se pressupõe fora do espírito de indivíduos reais, materialmente condicionados, um outro espírito à parte. Se a expressão consciente das relações reais deste indivíduo éilusória, se em suas representações põem a real idade de cabeça para baixo, isto é conseqüência de seu modo de atividade material limitado e das suas relações sociais limitadas que daí resultaram. ( $M$ arx eEngels, 1991, p 36)

No método dialético, $M$ arx distingue a representação do objeto do seu conceito. A representação situa-se no nível do senso comum, do mito, das formas ideologizadas do pensamento. 0 nível do conceito situa-se num nível mais el evado de abstração: a ciência, a filosofia etc. Contudo, representação e conceito são momentos interdependentes no conhecimento dialético, pois este vai do imediato ao mediato, da aparência à essência do objeto.

A diferença do pensamento de $M$ arx para o de Weber é que aquele faz o recorte de classe em contraposição ao termo geral e inespecífico de "sociedade" usado por Weber. M arx se aproxima dele quando diz que: 
A nova classe dominante é obrigada, para alcançar os fins a que se propõe, a apresentar seus interesses como sendo obrigada a emprestar a suas idéias a forma de universalidade e apresentá-las como sendo as únicas racionais, as únicas universalmente válidas. (M inayo apud Guareschi e ovchelovith, 1995, p. 74)

Para os autores, clássicos da sociologia, é no plano individual que as representações se expressam. M arx fala na obra Ideologia al emã de sujeitos históricos, ou de "indivíduos determinados", como portadores de uma forma determinada de relações sociais, políticas e econômicas. Durkheim chama a atenção para o fato de que as representações col etivas tendem a se individual izar nos sujeitos. E Weber nos diz que o indivíduo, enquanto portador de cultura e de valores social mente dados, é a "constelação singular", que informa sobre a ação social de seu grupo, tendo-se em conta que o limite de suas informações são seus valores, da mesma forma que os limites do conhecimento científico do pesquisador são seus próprios valores (M inayo apud Guareschi e ovchelovith, 1995).

Durkheim (1989), reafirmando a importância das representações, diz que o pensamento coletivo deve ser estudado tanto na sua forma como no seu conteúdo, por si e em si mesmo, na sua especificidade, pois uma representação social, por ser coletiva, já apresenta condições de objetividade. Portanto, as produções sociais não são realizações de indivíduos isolados, a partir de suas experiências sensíveis imediatas, como acredita a premissa empirista. 0 autor busca a origem dos conceitos, sustentando que estes formam a base do pensamento lógico para constituir a ferramenta para a comunicação das inteligências humanas.

0 conceito de representações coletivas compõe o quadro teórico analisado por Durkheim na relação indivíduo-sociedade. Ele foi o verdadeiro criador do conceito, na medida em que fixa os contornos e the reconhece o direito de explicar os fenômenos mais variados. Em suas concl usões, as representações coletivas são produções sociais, que, além de se distinguirem de qual quer sensação ou consciência particular e não dependerem dos sujeitos individuais para se produzirem e reproduzirem, ainda se impõem aos sujeitos de maneira coercitiva e genérica, como formas sociais de expressão, reconhecimento e explicação do mundo. As representações coletivas afiguram-se, portanto, como fatos sociais, ${ }^{1}$ não sendo fal sas ou verdadeiras, corretas ou incorretas. Elas são a forma como a coletividade humana, em cada tempo e em cada lugar, entende o mundo em que vive e expressa esse entendimento.

A s representações coletivas são o produto de uma imensa cooperação que se estende não apenas no espaço, mas no tempo; para produzilas, uma multidão de espíritos diversos associaram, misturaram, combinaram suas idéias e seus sentimentos; longas séries de gerações acumularam aí a sua experiência e o seu saber. U ma intelectualidade muito particular, infinitamente mais rica e mais complexa que a do indivíduo aí está como que concentrada. (Durkheim, 1989, p. 11)

A concepção dele, além de indicar uma diferença da sociedade em relação aos indivíduos isolados, também orienta a própria compreensão do processo representativo como fato social - de natureza distinta dos fenômenos individuais - , cujas causas e origem não podem ser encontradas senão na própria sociedade que o produziu.

Por meio do conceito de representações coletivas, Durkheim procura explicar a origem das chamadas "categorias do intelecto" - as noções essenciais que dominam a vida intelectual, formando um amplo arcabouço abstrato e impessoal, compartilhado por todos os membros de uma mesma civilização, cuja função é permitir a compreensão das propriedades mais universais das coisas e, desse modo, explicar sua existência. Essas "categorias do intelecto" são, na verdade, os conceitos que utilizamos para definir e caracterizar todas as coisas com as quais convivemos. Esse sistema de conceitos é expresso pelo vocabulário da nossa língua materna, sendo que "cada palavra traduz um conceito" (Durkheim, 1975).

Partindo da premissa racionalista de que o "mundo tem um aspecto lógico expresso de

1. "É fato social toda maneira de agir fixa ou não, suscetível de exercer sobre o indivíduo uma coerção exterior; ou então, ainda, que é geral na extensão de uma sociedade dada, apresentando uma existência própria, independente das manifestações individuais que possa ter" (Durkheim, 1974, p. 11). 
forma eminente pela razão" e negando a premissa empirista de que os indivíduos isolados produzem, a partir de suas experiências sensíveis imediatas, as formas de conhecimento e explicação do mundo compartilhadas pela coletividade, 0 autor busca as origens dos conceitos, que formam a base do pensamento lógico, constituindo-se na ferramenta para a comunicação das inteligências humanas (Durkheim, 1989, p. 43). Por serem mais estáveis do que as representações individuais, as representações coletivas são a base de onde se originam os conceitos, traduzidos nas palavras do vocabulário de uma comunidade, de um grupo ou de uma nação.

0 estudo da religião ocupa um espaço importante na obra durkheimiana. Partindo do postulado sociológico de que uma instituição humana tão duradoura e geral à humani dade não pode assentar-se no erro e na mentira, Durkheim busca conhecer, por meio do estudo das religiões primitivas, qual realidade humana elas expressam sob seus símbolos, tomando a religião como 0 mais primitivo fenômeno social. A s religiões das comunidades mais simples - onde é menor 0 desenvolvimento das individualidades e das diferenças e "o fato religioso ainda traz visível 0 sinal de suas origens" - mostram mais facilmente el ementos comuns a todas as sociedades (Durkheim, 1975).

0 interesse que o fez voltar-se às religiões era principalmente 0 de compreender as categorias fundamentais do entendimento humano, noções essenciais como tempo, espaço, número, causa, substância, personalidade. Essas são relações que existem entre as coisas e que, produzidas inicialmente no interior do pensamento religioso, são expressas por meio de conceitos e símbolos.

Durkheim questiona as duas teses que até então procuraram explicar a questão do conhecimento e de sua racionalidade - 0 empirismo e o apriorismo - e propõe que seja reconhecida a origem social das categorias, as quais traduziriam estados de coletividade, sendo, pois, produtos da cooperação. Enquanto os conhecimentos empíricos são suscitados pela ação do objeto sobre os espíritos dos indivíduos, as categorias seriam representações essencialmente coletivas, são obras da sociedade. São expressas inicial mente por meio da religião, na qual foi engendrado tudo o que há de essencial na sociedade: 0 direito, a ciência, a moral, a arte e a recreação. $E$ os homens não somente the deveram, numa proporção notável, a matéria de seus conhecimentos, senão também a forma segundo a qual esses conhecimentos são elaborados. Se isto se dá é porque "a idéia de sociedade é a alma da religião", e nesta se originaram quase todas as grandes instituições sociais. A religião é uma expressão resumida da vida coletiva (D urkheim, 1989).

Como é possível explicar as formas individualizadas de expressão e manifestação das representações coletivas, uma vez que elas são fatos sociais? 0 próprio Durkheim responde afirmando que, a despeito de serem produzidas de forma extrínseca aos indivíduos, as representações coletivas interiorizam-se nas consciências particulares e, por essa interiorização, individualizam-se, podendo adquirir formas e conteúdos diferenciados de sujeito para sujeito. Quanto maior for a diferenciação individual dentro de uma dada sociedade, mais elaboradas e com maior espaço na vida social tenderão a ser as formas particularizadas de expressão das representações coletivas (Durkheim, 1989).

Durkheim procura mostrar que a mentalidade do grupo não é a mesma que a dos indivíduos; que os estados de consciência coletiva são distintos dos estados de consciência individual, e que "um pensamento encontrado em todas as consciências particulares ou um movimento que todos repetem não são por isso fatos sociais", mas suas encarnações individuais. Os fenômenos que constituem a sociedade têm sua sede na coletividade e não em cada um dos seus membros. É nela que se devem buscar as explicações para os fatos sociais e não nas unidades que a compõem.

Os fatos sociais são formados pelas representações coletivas, isto é, "como a sociedade vê a si mesma e ao mundo que a rodeia", por meio de suas lendas, mitos, concepções religiosas, crenças morais etc. Segundo Durkheim $(1974$, p. 6),

a sociedade ideal não está fora da sociedade real, é parte dela, porque uma sociedade não está simplesmente constituída pela massa de indivíduos que a compõem, pelo solo que ocupam, pelas coisas que utilizam, pelos movimentos que efetuam, mas, antes de tudo, pela idéia que ela faz desi mesma. 
Para Durkheim, existe um conjunto de fenômenos que não são orgânicos, visto que consistem em representações e ações; como também não são psíquicos, pois não existem somente na consciência individual. São fatos que apresentam características muitos especiais. Consistem em maneiras de agir, de pensar e de sentir, exteriores ao indivíduo, e que são dotadas de um poder de coerção em virtude do qual esses fatos se impõem. Tais fatos constituem 0 objeto da sociologia e a distinguem da psicologia e da biologia.

Certos fatos sociais estão menos consolidados: são as chamadas maneiras de agir. É 0 caso das correntes sociais, dos movimentos coletivos, das correntes de opinião "que nos impelem com intensidade desigual, segundo as épocas e os países, ao casamento, por exemplo, ao suicídio ou a uma natalidade mais ou menos forte etc." (Durkheim, 1974) e que se expressam nas estatísticas. Outros fatos têm uma forma já cristalizada, que constituem as maneiras de ser sociais, como as regras jurídicas, morais, dogmas religiosos, sistemas financeiros, 0 sentido das vias de comunicação, nossa linguagem escrita etc. Elas são os leitos estabelecidos de circulação de pessoas e de mercadorias, os modos pelos quais muitas gerações se acostumaram a comunicar-se, a vestir-se, a edificar suas moradias, a negociar etc. A s maneiras de ser coletivas são de ordem anatômica ou morfológica; já os modos de agir são de ordem fisiológica, mas são igual mente imperativos, pois coagem a que se adotem determinadas condutas e formas de sentir. A lém disso, encontram-se fora dos indivíduos, são uma real idade objetiva e externa a el es, portanto são fatos sociais. L ogo, ambos possuem ascendência sobre o indivíduo, arrastando-o e influenciando-0.

Para tentar comprovar o caráter externo desses modos de agir ou de sentir, Durkheim argumenta que eles têm de ser internalizados por meio de um processo educativo. Desde muito pequenas, lembra, as crianças são constrangidas (ou educadas) a seguir horários, a desenvolver certos comportamentos e maneiras de ser e, mais tarde, a trabalhar. Elas passam por uma socialização metódica e é "uma ilusão pensar que educamos nossos filhos como queremos. Somos forçados a seguir regras estabelecidas no meio social em que vivemos" (Durkheim, 1955 , p. 47). Com o tempo as crianças vão adquirindo os hábitos que Ihe são ensinados e, deixando de sentir-lhes a coação, aprendem comportamentos e modos de sentir dos participantes do grupo onde vivem. Por isso a educação "cria no homem um ser novo", tornao um membro da sociedade, leva-o a compartilhar com outros uma certa escala de valores, sentimentos e comportamentos. A s maneiras de agir e sentir próprias de uma sociedade precisam ser transmitidas por meio da aprendizagem porque são externas ao indivíduo.

Outros cientistas sociais também utilizaram o conceito de representações para suas elaborações teóricas, como é o caso de Pierre Bourdieu.

Numa versão mais contemporânea, B ourdieu refere-se ao campo das representações sociais por meio da valorização da fala, como expressão das condições da existência. Para ele, a palavra é o símbolo da comunicação por excelência porque ela representa o pensamento. A fala, por isso mesmo, revela condições estruturais, sistemas de valores, normas e símbolos e tem a magia de transmitir, mediante um porta-v0z, as representações de grupos determinados, em condições históricas socioeconômicas e culturais específicas (Bourdieu, 1972).

B ourdieu, ao teorizar sobre a prática da pesquisa de campo, afirma que as condutas ordinárias da vida prestam-se a uma decifração, ainda que pareçam automáticas e impessoais. Elas são significantes, mesmo sem intenção de significar, e exprimem uma realidade objetiva que exige apenas a reativação da intenção vivida daqueles que as cumprem. Insiste Bourdieu (1972, p. 182) sobre a objetividade das representações:

Cada agente, ainda que não saiba ou que não queira, é produtor e reprodutor do sentido objetivo, porque suas ações são o produto de um modo de agir do qual ele não é o produtor imediato, nem tem o domínio completo.

Essa percepção do autor se vincula ao seu conceito de habitus. Este é determinado como uma espécie de lei "imanente" depositada em 
cada ator social, desde a primeira infância, a partir do seu lugar na estrutura social. São marcas das posições e situações de classe. $N$ essa perspectiva, as rel ações interpessoais não são apenas relações de indivíduos. É a posição presente e passada na estrutura social, que os indivíduos trazem consigo em forma de habitus em todo tempo e lugar, que marca a relação (M inayo apud Guareschi e J ovchelovith, 1995).

\section{Bases epistemológicas da teoria das representações sociais}

A concepção de representações sociais desenvolvida por Serge M oscovici tem proximidade com o conceito de representações coletivas desenvolvido por D urkheim. 0 próprio Moscovici reconhece ser esta a sua fonte de inspiração. Porém, apesar da proximidade, não são a mesma coisa.

M oscovici, consciente de que o modelo de sociedade pensado por D urkheim era estático e tradicional, preferiu substituir o conceito de "coletivo" por "social". Esse termo seria mais apropriado às sociedades complexas contemporâneas por serem dinâmicas e fluidas. 0 conceito de "coletivo" era mais apropriado àquele tipo de sociedade de dimensões cristal izadas e estruturadas, de conotação mais estática e positivista (M oscovici, 1981). Ele atribuiu, no caso das representações, não exatamente à sociedade como um ente invisível e indivisível, como fez Durkheim, mas sim aos grupos aos quais os indivíduos associam-se no decorrer de suas vidas. Grupos diferentes podem e tendem a produzir representações diferenciadas sobre um mesmo objeto.

A teoria das representações sociais se dirige à formação das explicações produzidas pelo senso comum, em sociedades complexas e não exatamente às formas de saber mais elaboradas ou estruturadas, como o mito, a religião, a linguagem, ou mesmo a ciência, que são melhor tratadas por meio do conceito durkheimiano de representações coletivas. N essa perspectiva abrangente, M oscovici (1981, p. 181) define representações sociais como

o conjunto de conceitos, proposições e explicações originado na vida diária no curso das comunicações interindividuais. Elas são 0 equivalente, na nossa sociedade, dos mitos e sistemas de crenças das sociedades tradicionais; elas podem também ser vistas como a versão contemporânea do senso comum.

M oscovici avalia que o conceito de representação coletiva ao incorporar uma diversidade de classes de conhecimento, tais como mitos, religião, ciência e categoria de tempo e espaço, dificulta a utilização do próprio conceito. A ssim, o autor constrói seu conceito fazendo duas modificações no conceito durkheimiano: as representações podem ser uma forma particular de construir conhecimento, como também uma forma de transmitir entre indivíduos conhecimentos adquiridos. Em outras palavras, as representações constituem modos de vida e formas de comunicação entre as pessoas; por isso, elas são representações sociais.

Enfim, a partir dessas elaborações acerca da relação indivíduo e sociedade, 0 autor se propõe a compreender o que seria uma sociedade pensante. Conforme Sá (1993, p. 28), na perspectiva psicossociológica de Moscovici, numa sociedade pensante,

os indivíduos não são apenas processadores de informações, nem meros portadores de ideologias ou crenças coletivas, mas pensadores ativos que, mediante inumeráveis episódios cotidianos, produzem e comunicam representações e soluções específicas para as questões que se colocam a si mesmos.

Segundo Sawaia (1995), M oscovici elaborou 0 conceito de representações sociais para colocar ênfase no sujeito que produz a representação, percebido como um ser criativo e ativo, contrapondo-o à concepção cognitivista que o posicionava como um ser passivo.

Celso Sá (1998) assegura que, quando decidimos real izar um estudo de representações sociais, o que queremos pesquisar é algum fenômeno de representação social. Podemos dizer que a construção do objeto de pesquisa é um processo pelo qual o fenômeno de representação social é simplificado e tornado compreensível pela teoria, para a finalidade da pesquisa. 
Os fenômenos de representação social estão "espalhados por aí": na cultura, nas instituições, nas práticas sociais, nas comunicações interpessoais e de massa e nos pensamentos individuais. Eles são, por natureza, difusos, fugidios, multifacetados, em constante movimento e presentes em inúmeras instâncias da interação social (Sá, 1998).

Os fenômenos de representação social são caracteristicamente construídos no que o psicólogo social e responsável pela "grande teoria" das representações sociais, Serge M oscovici, chamou de universos consensuais de pensamento. Os objetos de pesquisa que deles se derivam são tipicamente uma elaboração do universo reificado da ciência. Os universos consensuais de pensamento são regidos pela lógica natural ou senso comum, nos quais a participação é livre. Já os universos reificados são regidos pela lógica científica, nos quais a participação é condicionada pelo nível de qualificação.

Para M oscovici vivemos numa sociedade na qual os conhecimentos provenientes dos universos reificados da ciência e da tecnologia desencadeiam novos fatos, acontecimentos e situações que expõem os limites dos conhecimentos derivados dos universos consensuais do senso comum e com isso geram a sensação de estranhamento e de não-familiarização nos grupos sociais envolvidos com as mudanças.

A hipótese central proposta pelo autor é de que as representações sociais se desenvolvem justamente com o propósito de transformar al go não familiar em familiar, por meio de dois processos: objetivação e ancoragem.

A função de duplicar um sentido por uma figura, dar materialidade a um objeto abstrato, "naturalizá-Io", foi chamada de "objetivar". Segundo Moscovici (apud Sá, 1993, p. 40), "objetivar é descobrir a qualidade icônica de uma idéia ou ser impreciso, reproduzir um conceito em uma imagem". A objetivação seria o processo que torna concreto, por intermédio de uma figura, a idéia de um objeto.

A função de duplicar uma figura por um sentido, fornecer um contexto inteligível ao objeto, interpretá-lo, foi chamada de "ancorar". Segundo M oscovici (apud Sá, 1993, p. 38), ancorar é classificar e denominar: "coisas que não são classificadas nem denominadas são estranhas, não existentes e ao mesmo tempo ameaçadoras". Para ele, é possível, por meio das representações sociais, conservar as identidades sociais e orientar as condutas num mundo marcado por incessantes e rápidas transformações no modo de produzir e transmitir conhecimento (Sá, 1998). A ncorar também significa denominar. A denominação permite descrever as características das pessoas ou coisas, torna-as distintas e as torna objeto de convenção.

A ancoragem seria o processo de incorporar 0 aspecto não familiar dentro de uma rede de categorias que permita que ele seja comparado com elementos típicos dessas categorias. A ncorar significa classificar. Conforme Sá (1993, p. 39), a classificação ocorre por meio da escolha de paradigmas existentes com os quais se compara o objeto em processo de representação. Ele, porém, adverte:

não se trata, observe-se, de uma operação lógica de análise da proporção de características que o novo objeto tenha em comum com os objetos da classe. 0 que se põe em jogo é uma comparação generalizadora ou particularizadora, pelas quais se decreta que o objeto se inclui ou se af asta da categoria com base na coincidência/divergência em relação a um único ou poucos aspectos salientes que definem 0 protótipo. A lógica natural em uso nos universos consensuais preside 0 processo.

0 que Moscovici quer expressar com a proposição - "transformar al go não familiar em familiar" - é que, nas sociedades modernas, 0 novo é comumente gerado ou trazido à luz por meio dos universos reificados da ciência, da tecnologia ou das profissões especializadas. São novas descobertas ou teorias, invenções e desenvolvimentos técnicos, produções de fatos políticos eeconômicos, inovações classificatórias e analíticas, e assim por diante. A exposição a esse novo é que introduz a não-familiaridade ou a estranheza na sociedade mais ampla.

Se o estranho não se apresentasse tão freqüente e imprevisivelmente, o pensamento social humano teria a estabilidade que Durkheim atribuíra às representações coletivas. U ma realidade social, como a entende a teoria das 
representações sociais, é criada apenas quando o novo ou não-familiar vem a ser incorporado aos universos consensuais. Aí operam os processos pelos quais ele passa a ser familiar, perde a novidade, torna-se socialmente conhecido e real. Segundo M oscovici (apud Sá, 1993, p. 37),

o estranho atrai, intriga e perturba as pessoas e as comunidades, provocando nelas o medo da perda de referenciais habituais, do senso de continuidade e de compreensão mútua. Mas, ao tornar o estranho familiar, ele é tornado ao mesmo tempo menos extraordinário e mais interessante. (A pud Sá, 1993, p. 37)

J odelet, seguidora da perspectiva moscoviciana e propositora de uma abordagem cultural ista das representações sociais, sugere a seguinte definição sintética, sobre a qual parece existir hoje um amplo acordo dentro da comunidade de seus estudiosos: representações sociais são "uma forma de conhecimento, socialmente elaborada e partilhada, tendo uma visão prática e concorrendo para a construção de uma realidade comum a um conjunto social". I gualmente designada como saber de senso comum ou ainda saber ingênuo, natural, essa forma de conhecimento é diferenciada, entre outras, do conhecimento científico. Entretanto, é tida como um objeto de estudo tão legítimo quanto este, pela sua importância na vida social e pela elucidação possibilitadora dos processos cognitivos e das interações sociais (Sá, 1993).

Tanto M oscovici como J odel et enfatizam a ligação necessária do objeto de representação a um determinado sujeito. Ele propõe a fórmula: "toda representação é uma representação de al guém (o sujeito) e de al guma coisa (o objeto)" (J odelet, 2001, p. 27).

A representação social tem com seu objeto uma relação de simbolização (substituindo-o) e de interpretação (conferindo-Ihe significações). Trata-se de significações que são uma construção e uma expressão do sujeito - são, então, consideradas de um ponto de vista epistêmico e psicológico. M as a particularidade do estudo das representações sociais é o fato de integrar na análise desses processos a pertença e a participação, sociais ou culturais do sujeito (J odelet, 2001).
Para M oscovici, não existe um indivíduo abstrato, portador de esquemas mentais e lógicos universais aplicáveis a qualquer situação, mas sim indivíduos localizados em diferentes grupos sociais concretos, nos quais compartilham, constroem e reafirmam representações sociais.

Denise odelet (2001) privilegia um enfoque histórico e cultural para a compreensão do simbólico. Ela parte da noção básica de que uma representação social é uma forma de saber prático que liga um sujeito a um objeto. Três questões podem ser feitas acerca desse saber:

1) "Quem sabe e de onde sabe?", cujas respostas apontam para o estudo das condições de produção e circulação das representações sociais. Pesquisam-se as relações que a emergência e a difusão das representações sociais guardam com fatores, tais como: valores, modelos e invariantes culturais; comunicação interindividual, institucional e de massa; contexto ideológico e histórico; inserção social dos sujeitos, em termos de sua posição e filiação grupal; dinâmica das instituições e dos grupos pertinentes.

2) "O que e como se sabe?", que corresponde à pesquisa dos processos e estados das representações sociais. A pesquisa se ocupa dos suportes da representação (o discurso ou 0 comportamento dos sujeitos, documentos, práticas etc.), para daí inferir seu conteúdo e sua estrutura, assim como da análise dos processos de sua formação, de sua lógica própria e de sua eventual transformação.

3) "Sobre o que se sabe e com que efeito?", o que leva a uma ocupação com o estatuto epistemológico das representações sociais. Focal izam-se as relações que as representações guardam com a ciência e com o real, remetendo para a pesquisa das relações entre o pensamento natural e o pensamento científico, da difusão dos conhecimentos e da transformação de um tipo de saber em outro, bem como das decolagens entre a representação e o objeto representado, em termos de distorções, supressões e suplementações.

Celso Sá (1998) defende que, pelos padrões ideais, a simples descrição do conteúdo cognitivo de uma representação, sem relacioná-lo às condições socioculturais que favoreceram sua 
emergência e/ou sem uma discussão de sua natureza epistêmica em confronto com o saber erudito, não configura uma pesquisa real mente completa.

Jodelet (2001) afirma que as representações sociais, enquanto fenômenos complexos, apresentam diversos el ementos: informativos, cognitivos, ideológicos, normativos, crenças, valores, atitudes, opiniões, imagens etc. $E$ foi D urkheim o primeiro a identificar tais elementos como produções mentais sociais. Moscovici renovou a análise, apresentando a especificidade dos fenômenos representativos nas sociedades contemporâneas, que são caracterizadas por: intensidade e fluidez das trocas e comunicações; desenvolvimento da ciência; pluralidade e mobilidade sociais.

A s representações sociais, portanto, orientam e organizam as condutas e as comunicações sociais, assim como intervêm na difusão e na assimilação de conhecimentos, no desenvolvimento individual e coletivo, na definição das identidades pessoais e sociais, na expressão dos grupos e nas transformações sociais.

A "grande teoria" das representações sociais - como chamam as proposições originais básicas de Moscovici - desdobra-se em três correntes teóricas complementares: uma fiel à teoria original, com um caráter histórico e cultural, liderada por D enise J odelet, em Paris; uma que procura articulá-la com uma perspectiva mais sociológica, liderada por Willem Doise, em Genebra; e uma terceira que enfatiza a dimensão cognitivo-estrutural das representações por J ean-Claude A bric, em Provence.

$\mathrm{N}$ ão se trata de abordagens incompatíveis, na medida em que provêm todas de uma mesma matriz básica, conforme salienta Sá (1998). É, por exemplo, de Doise a consideração da perspectiva de Moscovici como uma "grande teoria", do que se depreende que as suas próprias proposições configurariam uma teoria complementar.

Doise (apud Jodelet, 2001, p. 193), recorrendo a Bourdieu, enfatiza que, mais que opiniões consensuais, as representações sociais são tomadas de posição simbólicas:

de um modo geral, pode-se dizer que, em cada conjunto de relações sociais, princípios ou esquemas organizam as tomadas de posição simbólicas ligadas a inserções específicas nessas relações. $E$ as representações sociais são os princípios organizadores dessas relações simbólicas entre atores sociais. Tratase de princípios relacionais que estruturam as relações simbólicas entre indivíduos ou grupos, constituindo ao mesmo tempo um campo de troca simbólica e uma representação desse campo.

Enfatizamos a importância dos dois universos de pensamento para a teoria das representações sociais. Nos universos consensuais, o indivíduo, com base no senso comum, é livre para manifestar opiniões, propor teorias e respostas para os problemas. $\mathrm{E}$ nos universos reificados, regidos pela lógica científica, 0 indivíduo tem sua participação condicionada pelo domínio reconhecido de um saber específico (Moscovici, 1981). Quais as modificações sofridas pelo conhecimento científico quando ele passa do domínio especial izado para o domínio popular?

Para M oscovici, essa é a indagação central da teoria e é nesse processo que surgem as representações sociais, como verdadeiras teorias do senso comum. Ele fez um estudo da psicanálise na França nos anos 50 e observou a incorporação del a por diferentes grupos sociais: os operários souberam dela através dos meios de comunicação de massas $(70 \%)$ e da conversação ( $40 \%$ ) e não tiveram contato com ela via estudos ( $0 \%)$. A o passo que estudantes e profissionais liberais obtiveram seu conhecimento por meio de estudos $(40 \%$ e $45 \%$ respectivamente). A psicanálise torna-se, portanto, objeto do senso comum (M oscovici, 1977).

Desenvolvemos a nossa pesquisa de mestrado partindo dessas proposições teóricas. Começamos indagando como o aluno incorpora os conhecimentos de sociologia, transmitidos por um profissional especializado (o professor ou a professora), em sua vida? Q ual o significado desses conhecimentos para a sua formação?

Finalizamos apresentando um quadro conceitual, síntese das concepções sobre representações na perspectiva da sociologia clássica e contemporânea e da psicol ogia social. 


\section{QUADRO CONCEITUAL DAS REPRESENTAÇÕES}

\begin{tabular}{|c|c|}
\hline Autor & Conceito \\
\hline SIMMEL & $\begin{array}{l}\text { As idéias ou representações são uma espécie de operador que permite ações } \\
\text { recíprocas entre os indivíduos para formar a unidade superior, que é a instituição } \\
\text { (partido político, Igreja etc.). Permite a passagem de um nível molecular para um } \\
\text { molar. }\end{array}$ \\
\hline WEBER & $\begin{array}{l}\text { Representação é um saber comum que tem o poder de antecipar e de prescrever o } \\
\text { comportamento dos indivíduos e de programá-lo. Ela constitui um quadro de } \\
\text { referências e um vetor da ação dos indivíduos. }\end{array}$ \\
\hline MARX & $\begin{array}{l}\text { As representações estão vinculadas à prática social. A manifestação da consciência se } \\
\text { faz por meio da linguagem e realiza um paralelo entre as duas entre as representações } \\
\text { e o real invertido, mostrando como as idéias estão comprometidas com as condições } \\
\text { de classe. A representação situa-se no nível do senso comum, do mito, das formas } \\
\text { ideologizadas do pensamento. }\end{array}$ \\
\hline DURKHEIM & $\begin{array}{l}\text { Estabeleceu a diferença entre representação individual e representações coletivas. Estas } \\
\text { são produções sociais, que além de se distinguirem de qualquer sensação ou } \\
\text { consciência particular e não dependerem dos sujeitos individuais para se produzirem e } \\
\text { reproduzirem, ainda impõem-se aos sujeitos de maneira coercitiva e genérica, como } \\
\text { formas sociais de expressão, reconhecimento e explicação do mundo. As } \\
\text { representações coletivas afiguram-se, portanto, como fatos sociais. }\end{array}$ \\
\hline BOURDIEU & $\begin{array}{l}\text { Refere-se ao campo das representações sociais mediante a valorização da fala, como } \\
\text { expressão das condições da existência. Para ele, a palavra é o símbolo da comunicação } \\
\text { por excelência porque ela representa o pensamento. A fala, por isso mesmo, revela } \\
\text { condições estruturais, sistemas de valores, normas e símbolos e tem a magia de } \\
\text { transmitir, por meio de um porta-voz, as representações de grupos determinados, em } \\
\text { condições históricas, socioeconômicas e culturais específicas. }\end{array}$ \\
\hline MOSCOVICI & $\begin{array}{l}\text { Diferenciou representações coletivas de representações sociais. Estas últimas } \\
\text { expressam o conjunto de conceitos, proposições e explicações originado na vida diária } \\
\text { no curso das comunicações interindividuais. Elas são o equivalente, na nossa } \\
\text { sociedade, dos mitos e sistemas de crenças das sociedades tradicionais. Elas podem } \\
\text { também ser vistas como a versão contemporânea do senso comum. Na perspectiva } \\
\text { psicossociológica do autor, os indivíduos não são apenas processadores de } \\
\text { informações, nem meros portadores de ideologias ou crenças coletivas, mas pensadores } \\
\text { ativos que, mediante inumeráveis episódios cotidianos, produzem e comunicam } \\
\text { representações e soluções específicas para as questões que se colocam a si mesmos. }\end{array}$ \\
\hline
\end{tabular}

\begin{abstract}
A bstract: This article presents a disaussion about the concept of representations in both classic and contemporary theory of sociology. Besides that, still shows the epistemological basis of the social representations' theory. The aim is to detach the different conceptions in both areas of knowledge - Sociology and Social Psychology - and to stand out that concept of Serge Moscovici's social representations came from the concept of Durkheim's collective representations.
\end{abstract}

K ey-words: epistemology; collective representations; social representations.

\section{Referências}

BOURDIEU, P. Squisse d'une théorie de la pratique. Paris: Librairie Droz, 1972.
DURK HEIM , Émile. Educação e sociologia. São Paulo: M elhoramentos, 1955.

. As regras do método sociológico. São Paulo: A bril, 1974. (Coleção Os Pensadores)

. A ciência social e a ação. Tradução de Inês D. Ferreira. São Paulo: Difel, 1975.

As formas elementares da vida religiosa. São Paulo: Edições Paulinas, 1989.

GUARESCHI, Pedrinho. "Sem dinheiro não há salvação": ancorando o bem e o mal entre os neopentecostais. In: GUARESCHI, Pedrinho; JOV CHELOV ITH, Sandra (Orgs.). Textos em representações sociais. Petrópolis: Vozes, 1995.

JODELET, Denise (Org.). As representações sociais. Tradução de Lilian Ulup. Rio de J aneiro: EdUERJ, 2001. 
MARX, K. \& ENGELS, F. A ideologia alemã. São Paulo: Hucitec, 1991.

M IN AY O, M . O conceito de representações sociais dentro da sociologia clássica. In: GUARESCHI; J OV CHEL OVITH (Orgs.). Textos em representações sociais. Petrópolis: Vozes, 1995.

M OSCOVICI, Serge. A representação social da psicanálise. Rio de J aneiro: Zahar, 1977.

. On social representations. In: FORGAS, J. P. (Ed.). Social cognition: perspective on everyday undertanding. L ondon: A cademic Press, 1981.

. Das representações coletivas às representaçôes sociais: elementos para uma história. In: JODELET, Denise (Org.). As representações sociais.
Tradução de Lilian U lup. Rio de J aneiro: EdUERJ, 2001.

SÁ , C. Representações sociais: o conceito e o estado atual da teoria. In: SPINK, M . J. (Org.). 0 conhecimento no cotidiano. São Paulo: Brasiliense, 1993.

A construção do objeto de pesquisa em representações sociais. Rio de J aneiro: UERJ, 1998. SAWA IA , Bader B. Representação e ideologia: um encontro desfetichizador. In: SPIN K, M ary J ane. 0 conhecimento no cotidiano: as representações sociais na perspectiva da psicologia social. São Paulo: Ed. B rasiliense, 1995.

WEBER, Max. A ética protestante e o espírito do capitalismo. São Paulo: Pioneira, 1985. 